\title{
Degeneration and Regeneration
}

National Cancer Institute

\section{Source}

National Cancer Institute. Degeneration and Regeneration. NCI Thesaurus. Code C120876.

A finding that generally has features of degeneration and regeneration. 